\title{
Dynamic Modeling and Analysis of Rolling Bearing with Compound Fault on Raceway and Rolling Element
}

\author{
Xin Zhang, Changfeng Yan (D), Yaofeng Liu, Pengfei Yan, Yubo Wang, and Lixiao Wu \\ School of Mechanical and Electronical Engineering, Lanzhou University of Technology, Lanzhou 730050, China \\ Correspondence should be addressed to Changfeng Yan; changf_yan@163.com
}

Received 2 July 2020; Revised 23 July 2020; Accepted 8 August 2020; Published 29 August 2020

Academic Editor: Jiawei Xiang

Copyright (@) 2020 Xin Zhang et al. This is an open access article distributed under the Creative Commons Attribution License, which permits unrestricted use, distribution, and reproduction in any medium, provided the original work is properly cited.

Rolling element bearing is a very important part of mechanical equipment and widely used in rotating machinery. Rolling element bearings could appear localized defects during the working condition, which would cause the complex vibration response of bearings. Considering the shaft and bearing pedestal, a 4 degree-of-freedom (DOF) dynamic model of rolling bearing with compound localized fault is established based on time-varying displacement, and the vibration characteristics of rolling bearing with localized faults under different conditions are investigated. The established model is verified by the experimental vibration signals in time domain and frequency domain. The results show that the vibration response of compound fault is the result of the coupling action of a single fault of rolling element and outer race. The influences of compound fault on the vibration signals of the bearing were analyzed under three conditions. With the increasing of radial load, defect size, and rotation speed, the vibration amplitude of bearing would increase correspondently, which would accelerate the failure rate of bearing and reduce the service life of bearing. This model is helpful to analyze the vibration response of the rolling element bearing with single or compound fault.

\section{Introduction}

As a basic mechanical component, rolling element bearings are widely used in precision machine tools, vehicles, and aerospace equipment. Rolling element bearings are prone to failure, such as pitting, cracking, spalling, and wear during long-term work. Vibration and noise will be generated when local defects appear on the raceway or rolling element surface of bearing. The defects would adversely affect the operation of the machine and the reliability of the rotating equipment. Therefore, it is urgent to build a dynamic model for bearing with local defect, which can speed up the study of characteristics of bearing failure.

Many efforts have been made in dynamic models for rolling bearings with local defects on the inner or outer raceway surface. McFadden and Smith [1] established the pulse sequence model for analyzing the vibration characteristics of a rolling bearing with single-point defect. A periodic impulse force model with Dirac function was constructed, and the variation rule of vibration characteristics of single-point defective rolling bearing was revealed under constant radial load. Su and Lin [2] extended this pulse sequence model and analyzed the vibration characteristics of deep groove ball bearings with single-point fault on the surface under time-varying load. In consideration of time-varying stiffness effects and load distribution on the bending vibration frequency of bearing rings, a 2-DOF dynamic model of rolling bearing was developed by Petersen et al. [3]. Singh et al. [4] described the process of the ball rolling over the defect zone of outer race in detail. It was found that several continuous short impulse forces are excited as the rolling element exiting out from the defective edge of raceway. Shaharohit and Kulkarni [5] established the finite element model with local defects of bearing on inner race and explored the bearing vibration characteristics under different working conditions. Considering the time-varying deflection excitation, the contact force between the rollers and the inner or outer raceway, and the influence of inertia force, sliding, and other factors, Wang et al. [6] established a multibody dynamic model of cylindrical bearing to explore the vibration response of a localized defect. Taking the centrifugal force, gyroscopic moment, kinetic characteristic 
of cage, and other factors into account, Niu et al. [7, 8] established a 6-DOF dynamic model of defect bearing to describe the vibration characteristics of the system under high speed. Considering the lubricating oil film, radial clearance, time-varying displacement, and stiffness, Yan et al. [9] presented a 5-DOF dynamic model for bearing with local defect based on isothermal elastohydrodynamic lubrication (EHL). Considering the sliding force of the rolling element and the interaction force between the cage and the raceway, Kang et al. [10] established an EHL model.

A model was proposed to calculate the deformation at sharp edges by Liu et al. [11], which can be used to study time-varying contact stiffness coefficients and time-varying displacement excitation between the rolling element and the edge of the defect as the roll passes through the defect area. In their further work, the improved model of raceway contact analysis for lubricating rolling elements was established on the basis of a model of time-varying impact force of local defects with different edge shapes [12]. A vibration response model of local defect in ball bearings was presented by Kong et al. [13], employing the Hertz contact stress distribution.

In addition, the vibration signals of rolling bearings with faulty rolling element have been paid more attention in the last two decades. Niu et al. [14] developed a dynamic model of localized defect on rolling element of angular contact ball bearing to discuss the influence of ball defect on the vibration of the bearing. Mishra et al. [15] built a dynamic model, considering the influence of bearing pedestal and rolling element defects based on the bond graph method. Choudhury and Tandon [16] introduced a discrete 3-DOF spring-mass-damper system to simplify the rolling bearing and constructed a defect excitation force using a rectangular pulse sequence. Arslan and Aktürk [17] established a massspring model to investigate the influence of defective and nondefective surfaces of rolling elements on bearing vibration by considering additional clearance. A 3-DOF spring-mass system was presented by Sassi et al. [18] to identify the pulse impact force by using kinematic energy method and researched the influences of ball defect on the vibration response of the ball bearing. By taking the contact between the raceway and ball as a spring-damping system into consideration, Cheng et al. [19] built a nonlinear dynamic model to investigate the vibration signals of the bearing under different faults. Yang et al. [20] presented a rotor-bearing-housing model which combined the finite element method with the lumped mass method. Subsequently, the effects of rolling element failure on the rotorbearing system were simulated. Combined with the nonlinear spring model at the contact point of the element and raceway, Yuan et al. [21] constructed a multibody dynamic model to explore the influence of a single defect and composite defect (including ball defect) in the presence of different bearing components.

In order to study the characteristics of vibration excited by single or multiple faults (compound faults) simultaneously in bearings, different dynamic models have been established to simulate and analyze further. Patel et al. $[22,23]$ constructed a 6-DOF dynamic model to analyze the vibration characteristics of single-point fault and complex fault on inner and outer ring surface of deep groove ball bearing. Yaqub et al. [24] built a multiplepoint defect dynamic model of composite fault bearing with considering the influence of location distribution of the defects on the vibration characteristics of the bearing. Considering the coupling excitation, time-varying displacement, and sliding of rollers, Wang et al. [25] built a 4DOF bearing-pedestal system model to investigate the response mechanism of complex fault-induced force and displacement excitation. In order to study the characteristics of vibration signals excited by a bearing with multipoint fault, Igarashi [26] established the models of two-point fault on the inner and outer raceway of bearing, respectively. The finite element model of a bearing with multipoint fault was simulated to analyze the characteristic frequency of the vibration signal caused by each fault point in detail [27]. Liu et al. [28, 29] proposed a personalized fault diagnosis method based on finite element simulation and extreme learning machine. This method could make the fault detection results more accurate and identify the faults more effectively.

Although there have been many research achievements on the vibration response characteristics caused by the compound fault bearing, especially the compound fault on inner and outer raceway surface, a few works focused on compound fault on surface of the rolling element and outer raceway. In this paper, considering the influences of coupling excitation and time-varying displacement excitation, a 4 -DOF dynamic model of deep groove ball bearing with compound fault is built. The model is verified by experimental results. The mechanism of vibration response induced by the compound fault is explored under different conditions.

The rest of this paper is arranged as follows: In Section 2, a 4-DOF dynamic model of deep groove ball bearing with compound fault is established. In Section 3, the dynamic equation is introduced. In Section 4, the simulated signals of the model are analyzed and compared with the experimental results. In Section 5, the vibration response of single and compound fault is researched under different conditions. The last section shows the conclusions.

\section{Establishment of the Dynamic Model}

The following reasonable assumptions are given in this model to simplify the shaft-bearing-pedestal system shown in Figure 1(a):

(i) The rolling elements contact with the raceway is Hertz contact and the plastic deformation of the contact interface material can be neglected

(ii) The rolling elements are evenly distributed

(iii) Both the inertia effect of the rolling element and the gyroscope moment are neglected under the mediun and low speed conditions

(iv) For the early defect of bearing, the size of defect depth and width is much smaller than the diameter 


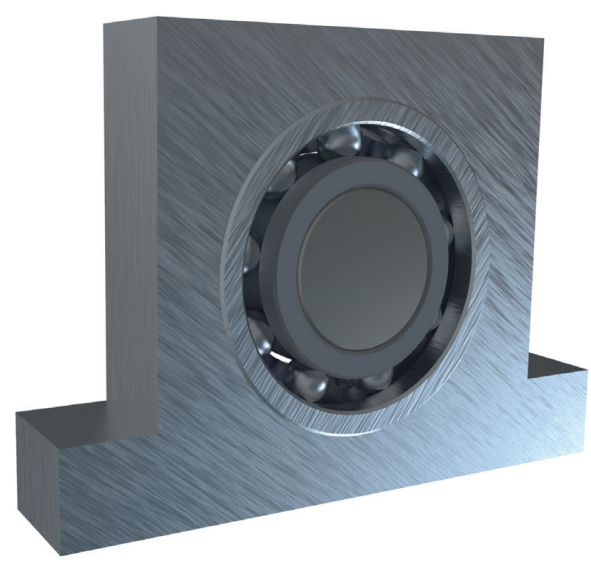

(a)

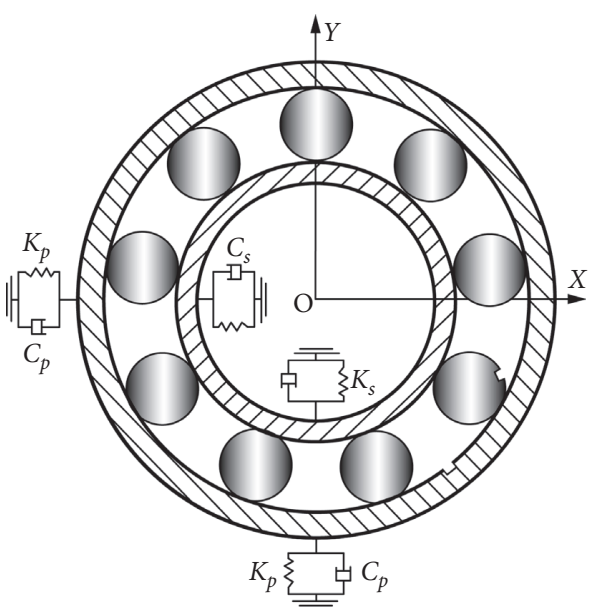

(b)

FIgURE 1: Simplified model of rolling bearing. (a) Shaft-bearing-pedestal system. (b) Simplified model.

of ball; the curvature radius of the defect edge is much smaller and can be ignored

The contact between the rolling element and the inner and outer raceway is simplified as a mass-spring-damper system. A simplified 4-DOF model for the bearing system is shown in Figure 1(b). $K_{s}$ and $C_{s}$ are the contact stiffness and damping between inner race and shaft, respectively; the contact stiffness between outer race and bearing pedestal is $K_{p}$ and damping is $C_{p}$.

2.1. Ball Defect. The rolling element defect would contact with the inner or outer raceway during the rolling bearing rotating. Due to the unpredictability of the rotation path of the ball, it is assumed that the rolling element defect only has planar motion.

A diagrammatic sketch of the contact between the inner raceway and the rolling element with the local defect is shown in Figure 2. The defect is defined as a rectangular spall in this model, $L$ is the width of damage, $D_{L}$ is the depth, $R$ is the radius of the rolling element, $\omega_{s}$ is the rotation speed of bearing, and $\omega_{b}$ is the rotating speed of the rolling element.

When the defect in element contact with the outer or inner raceway, the radial elastic deformation changes instantaneously. The radial elastic deformation $\delta_{b j}$ is expressed as

$$
\delta_{b j}=x \cos \theta_{j}+y \sin \theta_{j}-C_{r}-\beta_{j} \lambda_{b} .
$$

$\theta_{j}=\omega_{c} t+2 \pi(i-1) / Z$ is the position angle of the $j$ th rolling element, $\omega_{c}$ is rotating speed of cage, $C_{r}$ is the radial clearance, $Z$ is the number of rolling elements; $x$ is horizontal displacement, $y$ is vertical displacement, $\lambda_{b}$ is the timevarying radial displacement, and $\beta_{j}$ is switching quantity.

The maximum radial displacements in the inner race and outer race are $H_{i \max }$ and $H_{\text {omax }}$ as shown in Figure 3, respectively, which can be expressed as follows:

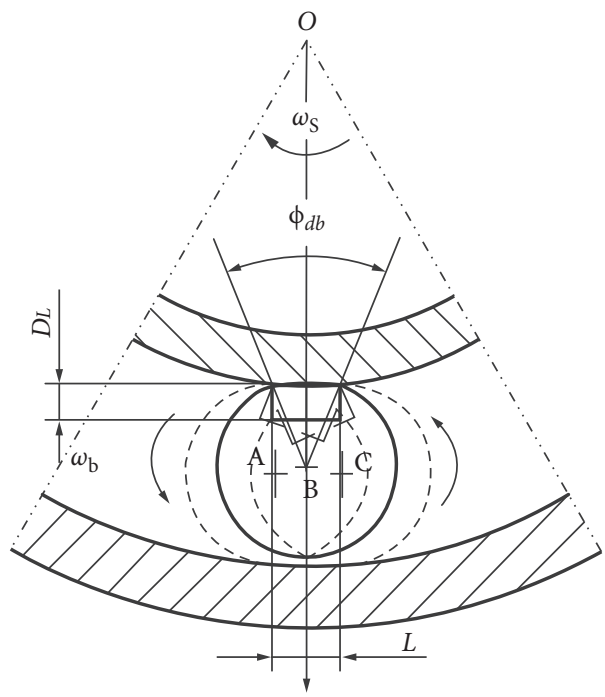

Figure 2: Motion of defective ball on raceway.

$$
\begin{aligned}
& H_{\text {imax }}=r_{i}-\sqrt{r_{i}^{2}-\left(\frac{L}{2}\right)^{2}}, \\
& H_{o \max }=r_{o}-\sqrt{r_{o}^{2}-\left(\frac{L}{2}\right)^{2}},
\end{aligned}
$$

where $r_{i}$ and $r_{o}$ are the raceway radius of the inner race and outer race, respectively.

The defect on rolling element surface would contact the outer raceway and the inner raceway every time within one cycle; therefore, an impact pulse is excited every time. The $j$ th ball is assumed to be damaged; then, the position of the defect on rolling element surface at time $t$ is shown in the following equation:

$$
\phi_{j}=\omega_{b} t+\phi_{\text {defect }}+\frac{2 \pi(j-1)}{Z},
$$




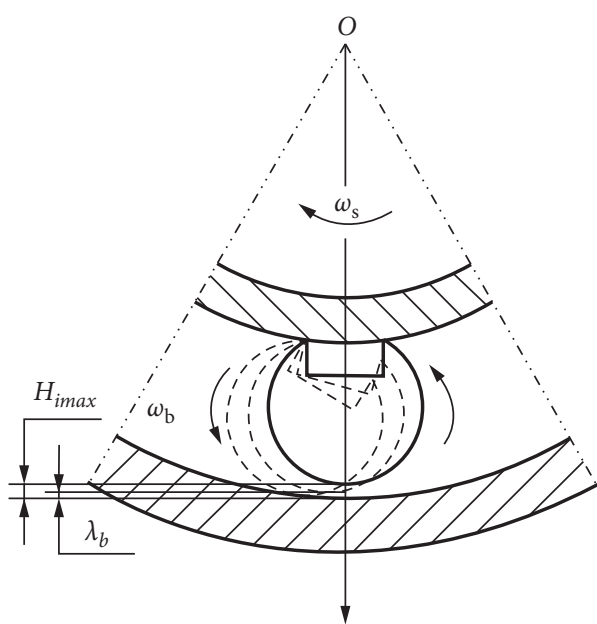

(a)

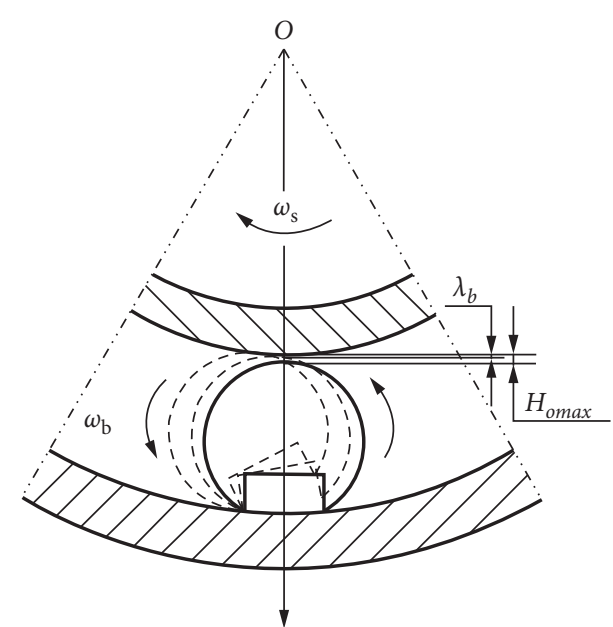

(b)

Figure 3: (a) Fault on rolling element contact with inner raceway. (b) Fault on rolling element contact with outer raceway.

where $\phi_{\text {defect }}$ is the initial position angle of the ball defect, and it is defined as the angle between the element defect and the radial radius of the outer raceway contact point as shown in Figure 4(a).

If the defect on rolling element surface contacts the inner raceway or outer raceway as shown in Figure 3, the radial displacement would be changed, and the following equation should be met:

$$
\begin{cases}\left|\bmod \left(\frac{\phi_{j}}{2 \pi}\right)-\pi\right|<\phi_{\mathrm{db}}, & \text { inner race, } \\ \left|\bmod \left(\frac{\phi_{j}}{2 \pi}\right)\right|<\phi_{\mathrm{db}}, & \text { outer race, }\end{cases}
$$

where damage angle $\phi_{\mathrm{db}}=\arcsin (0.5 L / r) ; r$ is radius of rolling element.

Based on this above analysis, the radial displacement caused by contact between defect on rolling element and inner or outer raceway can be obtained as follows:

$$
\lambda_{b}= \begin{cases}D_{L}, & D_{L}<H_{\max } \\ H_{\max }, & D_{L} \geq H_{\max }\end{cases}
$$

When the defect on rolling element contacts the outer raceway, $\beta_{j}$ in equation (1) is as follows [30]:

$$
\beta_{j}= \begin{cases}1, & 2 n_{j} \pi+\phi_{\text {defect }} \leq \omega_{b} t \leq 2 n_{j} \pi+\phi_{\text {defect }}+\phi_{\mathrm{db}} \\ 0, & \text { others. }\end{cases}
$$

When the defect on rolling element contacts the inner raceway, $\beta_{j}$ is as follows:

$$
\beta_{j}= \begin{cases}1, & \left(2 n_{j}+1\right) \pi+\phi_{\text {defect }} \leq \omega_{b} t \leq\left(2 n_{j}+1\right) \pi+\phi_{\text {defect }}+\phi_{\mathrm{db}}, \\ 0, & \text { others, }\end{cases}
$$

where $n_{j}$ is the number of rotations of rolling element.
When the defect on rolling element contacts the outer raceway,

$$
n_{j}=\operatorname{int}\left(\frac{\omega_{b} t}{2 \pi}\right) .
$$

When the defect on rolling element contacts the inner raceway,

$$
n_{j}= \begin{cases}\operatorname{int}\left(\frac{\omega_{b} t}{2 \pi}\right), & \phi_{\text {defect }}<\pi, \\ \operatorname{int}\left(\frac{\omega_{b} t}{2 \pi}\right)+1, & \phi_{\text {defect }} \geq \pi .\end{cases}
$$

2.2. Outer Defect. When the localized fault on the outer raceway contacts the rolling element, the contact stress on the contact surfaces would suddenly change, which would result in an impact vibration. Assuming that the outer raceway damage is pitting, the width is $b$, the depth is $D_{b}$, and the damage angle is $\phi_{d o}$.

The localized fault on the outer raceway of bearing could be described as in Figure 4. Figure 4(a) shows that when the rolling element rolls across the local defect at a certain point of the outer raceway, the deformation of the $i$ th rolling element may be expressed as follows:

$$
\delta_{b i}=x \cos \theta_{i}+y \sin \theta_{i}-C_{r}-\beta_{i} \lambda_{o},
$$

where $\theta_{i}=\omega_{c} t+2 \pi(i-1) / Z$ is the position angle of the $i$ th rolling element, $\omega_{c}$ is the rotating speed of cage, $C_{r}$ is the radial clearance, $Z$ is the number of rolling elements; $x$ is horizontal displacement, $y$ is vertical displacement, $\lambda_{o}$ is the time-varying radial displacement of rolling element passing through the fault on outer raceway, and $\beta_{i}$ is switching quantity.

When the rolling element comes across the localized fault on the outer raceway, the maximum of time-varying displacement of raceway could be given as follows: 


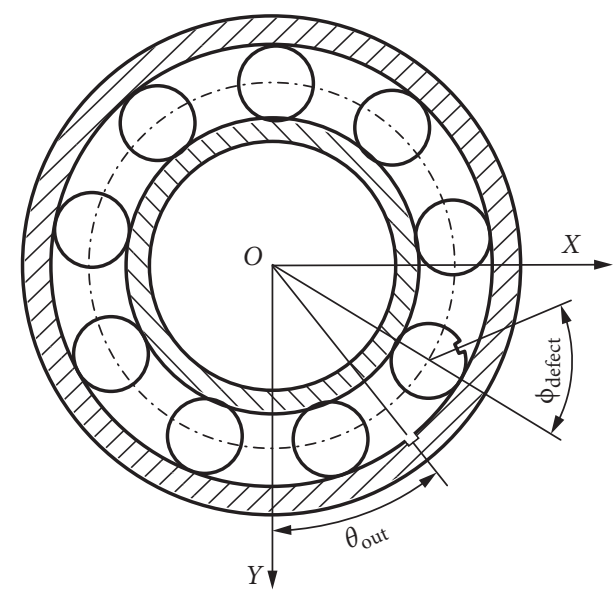

(a)

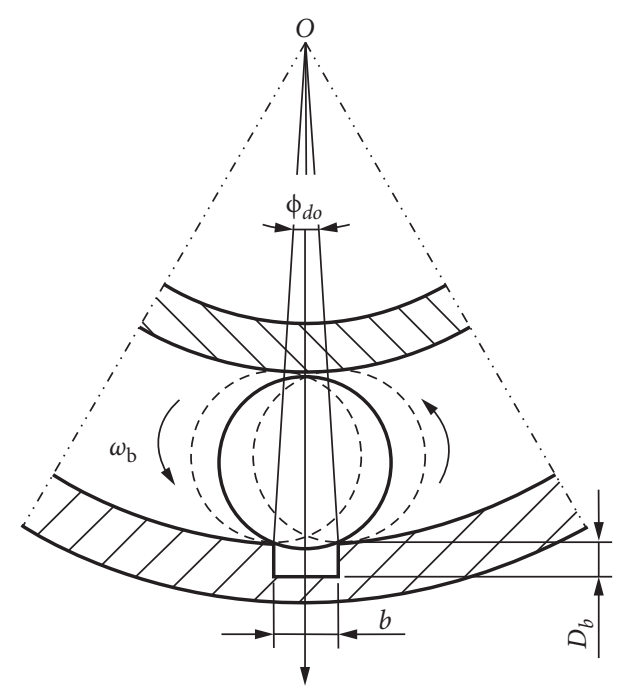

(b)

FIGURE 4: Simulation model of local defect on outer raceway.

$$
H_{\max }=r_{o}-\sqrt{r_{o}^{2}-\left(\frac{b}{2}\right)^{2}}
$$

$\lambda_{o}$ can be obtained by the following equation:

$$
\lambda_{o}= \begin{cases}D_{b}, & D_{b}<H_{\max }, \\ H_{\max }, & D_{b} \geq H_{\max } .\end{cases}
$$

When the $i$ th rolling element enters into the defect zone on the outer raceway of bearing, $\beta_{i}$ is given in the following equation:

$$
\beta_{i}= \begin{cases}1, & \theta_{\text {out }}-\phi_{\mathrm{do}} \leq \bmod \left(\frac{\theta_{i}}{2 \pi}\right) \leq \theta_{\text {out }}+\varphi_{\mathrm{do}}, \\ 0, & \text { others }\end{cases}
$$

where $\phi_{\mathrm{do}}=\arcsin \left(0.5 b / r_{o}\right)$ is the damage angle of local defect on outer raceway.

\section{Dynamic Equation}

The Hertz contact force between the rolling element and the raceways is dependent on whether the rolling element is in the position of the load zone or not. As is shown in Figure 5, when the ball is situated in the unload zone, it is indicated that the rolling element is not in direct contact with the raceway. Otherwise, the rolling element and raceways are in Hertz contact. Therefore, a Dirac function $\xi$ is used to estimate the position of the rolling element in the load zone, as is shown in (18).

Simplify each rolling element as a parallel mass-springdamping system (shown in Figure 1(b)).

The rolling element contact stiffness of rolling element and inner or outer raceway is calculated by the following equation [31]:

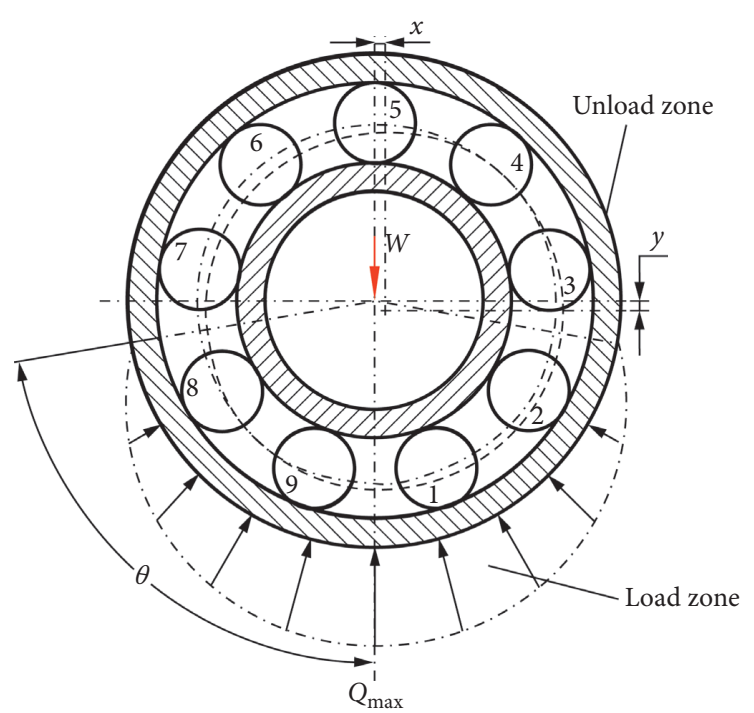

FIgURE 5: Schematic of rolling bearing load distribution.

$$
\left\{\begin{array}{l}
k_{i}=\frac{2 \sqrt{2}\left(E / 1-\mu^{2}\right)}{3\left(\sum \rho_{i}\right)}\left(\frac{1}{\delta_{i}^{*}}\right)^{3 / 2}, \\
k_{o}=\frac{2 \sqrt{2}\left(E / 1-\mu^{2}\right)}{3\left(\sum \rho_{o}\right)}\left(\frac{1}{\delta_{o}^{*}}\right)^{3 / 2} .
\end{array}\right.
$$

where $E$ is the elastic modulus, $\mu$ is the Poisson ratio; $k_{i}$ and $k_{o}$ are the contact stiffness between the rolling element and the outer and inner raceways, respectively; $\sum \rho_{i}$ is the curvature and $\delta_{i}^{*}$ is the contact displacement of the inner raceway, respectively; $\sum \rho_{o}$ is the curvature and $\delta_{o}^{*}$ is the contact displacement of the inner raceway, respectively. 
As shown in Figure 6, the contact stiffness of the rolling element with the inner and outer raceways is equivalent to $K_{i o}$ :

$$
K_{i o}=\frac{1}{\left(1 / k_{i}^{1.5}+1 / k_{o}^{1.5}\right)^{3 / 2}} .
$$

Based on the Hertz contact theory, the relationship of contact load and displacement of rolling bearing is

$$
F=K \delta_{b j}^{3 / 2}
$$

where $K$ is Hertz contact stiffness.

$F_{x}$ and $F_{y}$ are the total Hertz contact forces in horizontal and vertical directions, which can be expressed as follows:

$$
F_{x}=\sum_{j=1}^{z} K_{i o} \xi \delta_{b j}^{3 / 2} \cos \theta_{i}, F_{y}=\sum_{j=1}^{z} K_{i o} \xi \delta_{b j}^{3 / 2} \sin \theta_{i},
$$

where

$$
\xi= \begin{cases}1, & \delta_{b j}>0 \\ 0, & \delta_{b j} \leq 0\end{cases}
$$

Radial deformation with single fault on rolling element surface is

$$
\delta_{b j}=\left(x_{s}-x_{p}\right) \cos \theta_{i}+\left(y_{s}-y_{p}\right) \sin \theta_{i}-C_{r}-\beta_{j} \lambda_{b} .
$$

The total radial deformation with compound fault is

$$
\delta_{b j}=\left(x_{s}-x_{p}\right) \cos \theta_{i}+\left(y_{s}-y_{p}\right) \sin \theta_{i}-C_{r}-\beta_{j} \lambda_{o+b} \text {. }
$$

where $\lambda_{o+b}$ is the time-varying displacement when rolling elements roll over defect on the outer raceway and defect on rolling element contacts with the inner or outer raceway

The dynamic equations of the rolling element bearing with compound defects on the surfaces of the rolling element and outer raceway are shown as follows:

$$
\left\{\begin{array}{l}
M_{s} \ddot{X}_{s}+C_{s} \dot{X}_{s}+K_{s} X_{s}+F_{x}=W_{x}, \\
M_{s} \ddot{Y}_{s}+C_{s} \dot{Y}_{s}+K_{s} Y_{s}+F_{y}=W_{y}, \\
M_{p} \ddot{X}_{p}+C_{p} \dot{X}_{p}+K_{p} X_{p}-F_{x}=0 \\
M_{p} \ddot{Y}_{p}+C_{p} \dot{Y}_{p}+K_{p} Y_{p}-F_{y}=0,
\end{array}\right.
$$

where $W_{x}$ and $W_{y}$ are the applied loads of the rolling bearing system in the $X$ - and $Y$-directions, respectively.

According to Figure 7, it shows the flow chart of solving (21) based on the fourth-order Runge-Kutta method.

\section{Experimental Verification}

4.1. Experimental Test Rig. The MFS test rig produced by Spectra Quest Incorporation (SQI) is used to test the local fault on the outer raceway and rolling element surface of bearing, which is shown in Figure 8. In this experiment, the shaft was driven by a $1 \mathrm{HP} 3$-phase AC motor at $1750 \mathrm{rpm}$. The motor is connected with the shaft by a flexible coupling. The shaft was supported by two deep groove bearings ER-

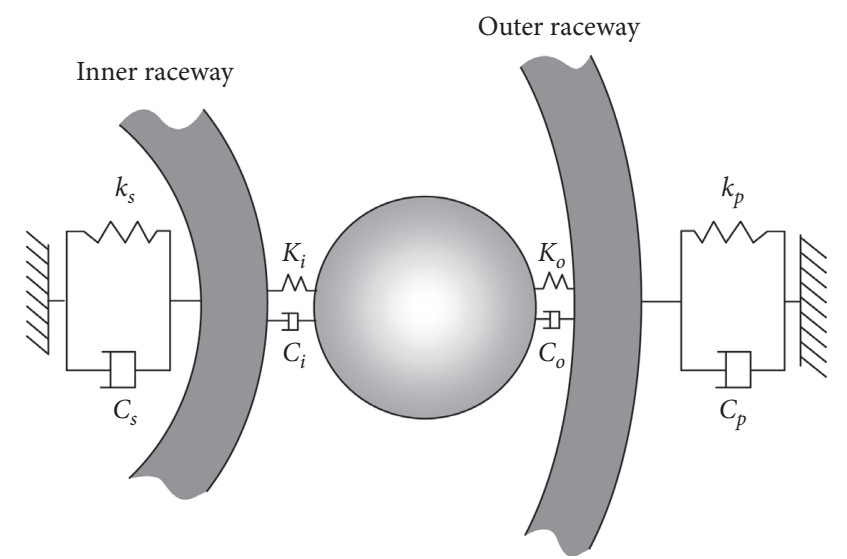

FIgURE 6: Simplified model of the bearing.

$16 \mathrm{k}$; one is localized defect bearing and the other is a healthy bearing. A $50 \mathrm{~N}$ radial load was put on the shaft by a $5.1 \mathrm{~kg}$ rotor disk installed in the middle of the two bearings. A DAQ acquisition card of portable spectra PAD connected between the accelerometer by a 3-channel data cable and a computer by USB port was used to collect the acceleration signal of vibration.

The ER-16K deep groove ball bearing is used in the experiment. The test bearings with defects fabricated by laser etching technique are shown in Figure 9, and the specific parameters of the test bearing are shown in Table 1 .

The characteristic frequency of the outer raceway $\left(f_{\mathrm{BPFO}}\right)$ and the rolling element $\left(f_{\mathrm{BPB}}\right)$ are given in the following equations [16]:

$$
\begin{aligned}
f_{\mathrm{BPFO}} & =\frac{Z}{2}\left(1-\frac{d}{D_{m}} \cos \alpha\right) f_{s}, \\
f_{\mathrm{BPB}} & =\frac{D_{m}}{d}\left(1-\frac{d}{D_{m}} \cos \alpha\right) f_{s} .
\end{aligned}
$$

For the model, the radial load is set to $W_{x}=50 \mathrm{~N}$ and $W_{y}=0 \mathrm{~N}$. The initial values of the displacements are $X_{s}=0 \mathrm{~m}, Y_{s}=0 \mathrm{~m}$ and $X_{p}=0 \mathrm{~m}, Y_{p}=0 \mathrm{~m}$, and the initial velocity is $0 \mathrm{~m} / \mathrm{s}$.

4.2. Ball Defect. In the simulation model, the outer race of is fixed with the bearing pedestal, and the inner race rotates with the shaft.

When the speed is $1750 \mathrm{r} / \mathrm{min}$, the characteristic frequency $f_{\mathrm{BPB}}$ is $135.5 \mathrm{~Hz}$ according to (23).

The simulated signals of vibration of bearing with rolling element defect are shown in Figure 10. When the localized defect occurs on the rolling element surface, there are significant periodic shocks in the simulated signal in time domain as shown in Figure 10(a), and enlarged simulated acceleration signals from $1.4 \mathrm{~s}$ to $1.44 \mathrm{~s}$ are given in Figure 10(b). It is shown in Figure 10(b) that 5 impulses generate when the rolling element defect contacts the inner and outer raceways during $0.04 \mathrm{~s}$. Meanwhile, the time intervals between impulse are approximately $7.38 \mathrm{~ms}$, equaling $1 / f_{\mathrm{BPB}}$. It is observed from Figure $10(\mathrm{c})$ that the fault 


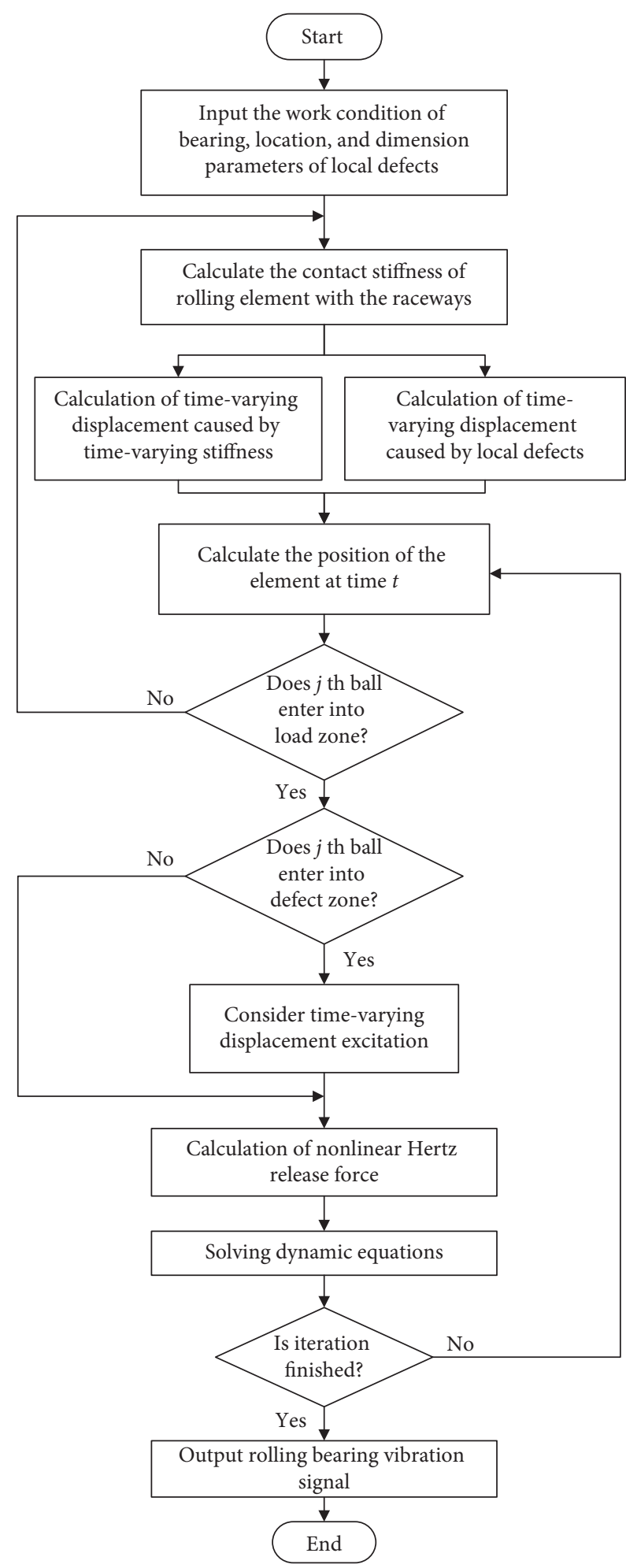

Figure 7: Flowchart of solution procedure.

characteristic frequency $\left(f_{\mathrm{BPB}}\right)$ of rolling element is $135.5 \mathrm{~Hz}$, which is consistent with the theoretical value. The harmonics $2 \mathrm{x}$ and $3 \mathrm{x}$ of $f_{\mathrm{BPB}}$ can be seen clearly.

The defective rolling element of the testing bearing is shown in Figure 9(a). The diameter of the defect on rolling element surface is $1.2 \mathrm{~mm}$, consistent with the simulated model. The vibration signals of testing bearing in both time domain and frequency domain from the experimental results are shown in Figure 11. The enlarged experimental acceleration signals from $1.4 \mathrm{~s}$ to $1.43 \mathrm{~s}$ are given in Figure 11(b). It is shown in Figure 11(b) that the time intervals between impulse are approximately $7.38 \mathrm{~ms}$, equaling $1 / f_{\mathrm{BPB}}$. Simulated signals and experimental signals are basically consistent in time domain. Therefore, the reliability of the proposed model is verified.

Comparing Figure 10(c) with Figure 11(c), it is shown that the fault characteristic frequencies of rolling element from the simulated signal and experimental results are $135.5 \mathrm{~Hz}$ and $136.5 \mathrm{~Hz}$, respectively. The relative error between experimental and simulated results is $0.74 \%$ and very small. The established model fits the experimental results very well; therefore, this model is correct and could be utilized to analyze the vibration response of faulty rolling bearing.

4.3. Compound Fault. The simulation model of the bearing with compound fault is built, in which the width of defect on the outer raceway is $1.2 \mathrm{~mm}$ and the diameter of defect on rolling element surface is $1.2 \mathrm{~mm}$. The defect on outer raceway is situated at 6 o' clock.

When the speed is $1750 \mathrm{r} / \mathrm{min}$, the characteristic frequency $f_{\mathrm{BPFO}}$ is $104.19 \mathrm{~Hz}$ based on (22).

The simulated vibration signals of bearing with compound fault are shown in Figure 12. Because the localized defects are on the surfaces of both rolling element and outer raceway, it is shown in Figure 12(a) that the significant periodic impulses occur in the simulated signal in time domain. Enlarged simulated acceleration signals in time domain from $1.56 \mathrm{~s}$ to $1.66 \mathrm{~s}$ are shown in Figure 12(b). It can be seen from the amplified diagram in time domain that impulses $\mathrm{A} 1$ and $\mathrm{A} 2$ are generated when the rolling element roll over the outer raceway defect, and impulses B1 and B2 occur when the rolling element defect contacts with inner or outer raceway. Meanwhile, the time intervals between impulses are approximately $9.3 \mathrm{~ms}$ and $7.38 \mathrm{~ms}$, equaling $1 / f_{\mathrm{BPFO}}$ and $1 / f_{\mathrm{BPB}}$, respectively. It could be observed from Figure $12(\mathrm{c})$ that $f_{\mathrm{BPFO}}$ and $f_{\mathrm{BPB}}$ are $104.4 \mathrm{~Hz}$ and $135.5 \mathrm{~Hz}$, respectively, which are consistent with the theoretical value. The harmonics $2 \mathrm{x}$ and $3 \mathrm{x}$ of $f_{\mathrm{BPFO}}$ and $f_{\mathrm{BPB}}$ can be also seen clearly.

The diameter of the defect on rolling element surface of the testing bearing is $1.2 \mathrm{~mm}$ and shown in Figure 9(a). The width and depth of the defect on the outer raceway surface of the testing bearing are $1.2 \mathrm{~mm}$ and $0.25 \mathrm{~mm}$, respectively, which is shown in Figure 9(b). The defects on testing bearing are consistent with the simulated model.

The vibration response of testing bearing with compound fault in both time domain and frequency spectrum from the experiment are shown in Figure 13. Enlarged experimental signals in time domain from $1.56 \mathrm{~s}$ to $1.66 \mathrm{~s}$ are given in Figure 13(b). It can be seen from the amplified diagram in time domain that impulses A3 and A4 are generated when the rolling element roll over the outer raceway defect, and impulses B3 and B4 occur when the rolling element defect contacts with inner or outer raceway. Meanwhile, the time intervals between impulse are 


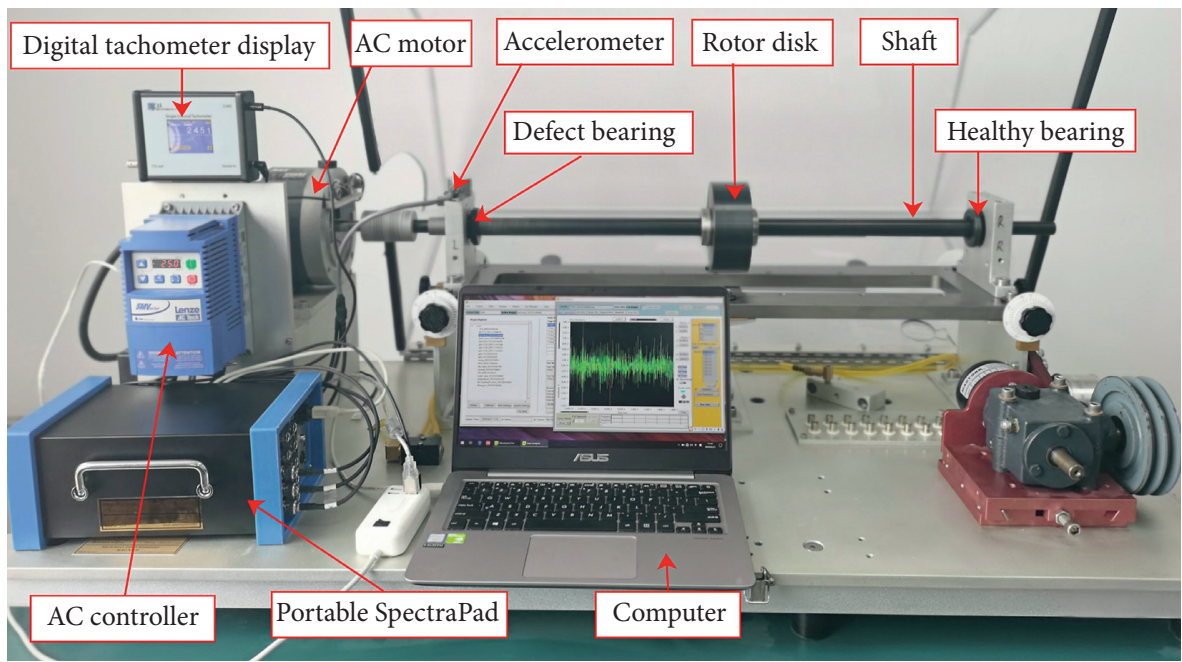

Figure 8: MFS test rig.

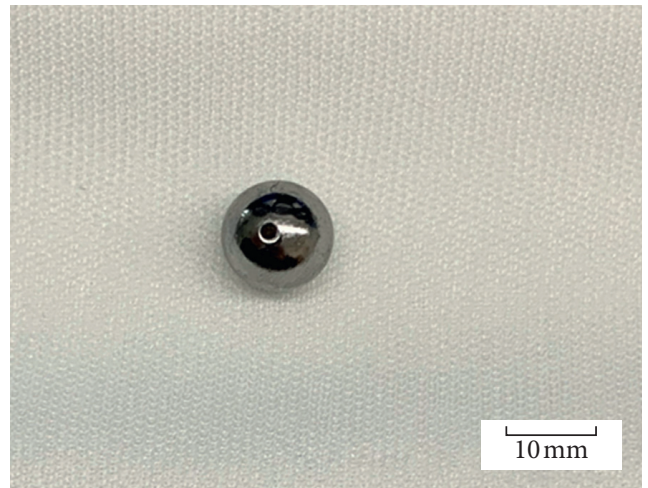

(a)

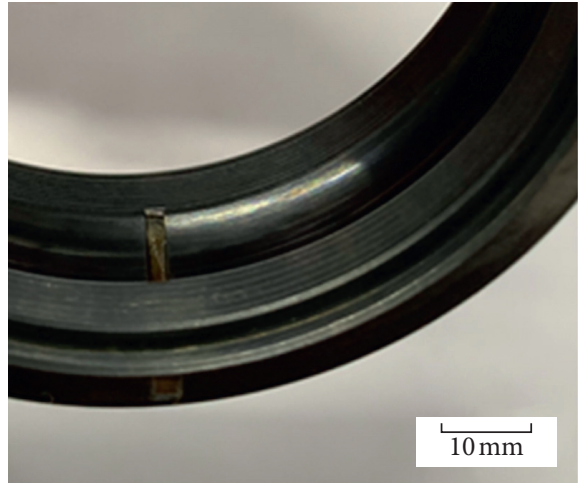

(b)

Figure 9: The tested rolling bearing with defect. (a) Rolling element with defect. (b) Outer raceway with defect.

TABLE 1: Parameters of ER-16K deep groove ball bearing.

\begin{tabular}{lcc}
\hline Parameter & Value & Unit \\
\hline Inner race dimension, $D_{i}$ & 30.59 & $\mathrm{~mm}$ \\
Outer race dimension, $D_{o}$ & 46.47 & $\mathrm{~mm}$ \\
Pitch dimension, $D_{m}$ & 38.51 & $\mathrm{~mm}$ \\
Ball dimension, $d$ & 7.94 & $\mathrm{~mm}$ \\
Number of balls, $Z$ & 9 & $\mathrm{~mm}$ \\
Radial clearance, $\mu$ & 0.045 & \\
\hline
\end{tabular}

approximately $9.3 \mathrm{~ms}$ and $7.38 \mathrm{~ms}$, equaling $1 / f_{\mathrm{BPFO}}$ and $1 /$ $f_{\mathrm{BPB}}$, respectively. From figures in time domain, it is clearly shown that the simulated and experimental signals of bearing with compound fault have periodic impact phenomenon in the time domain.

It could be seen from Figure 12(c) and Figure 13(c) that $f_{\mathrm{BPFO}}, f_{\mathrm{BPB}}$ and their harmonics frequency are clearly visible. The fault characteristic frequencies of $f_{\mathrm{BPFO}}$ and $f_{\mathrm{BPB}}$ are 104.7 Hz and $139.6 \mathrm{~Hz}$, respectively. The relative errors of $f_{\mathrm{BPFO}}$ and $f_{\mathrm{BPB}}$ between experimental and simulated results are $0.29 \%$ and $3.02 \%$, respectively; therefore, the simulation model is agreeable with the experimental results. The relative errors are related to the preload, rolling element sliding, and other factors.

Comparing Figure 10(c) with Figure 12(c), it can be clearly seen that when the rolling element bearing has compound fault, the amplitudes of fault characteristic frequency are larger than those with single defect. The vibration response of bearing with compound fault is the result of the coupling of the vibration signals from the single fault on the surfaces of rolling element and the outer raceway. 


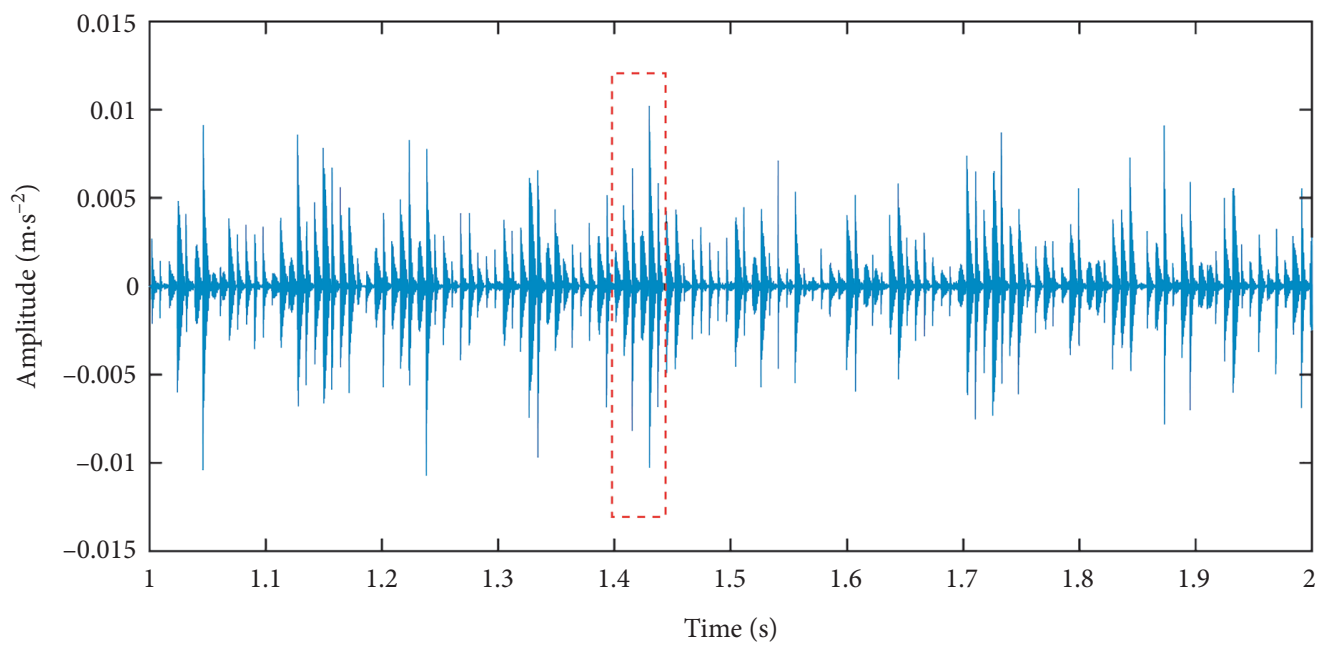

(a)

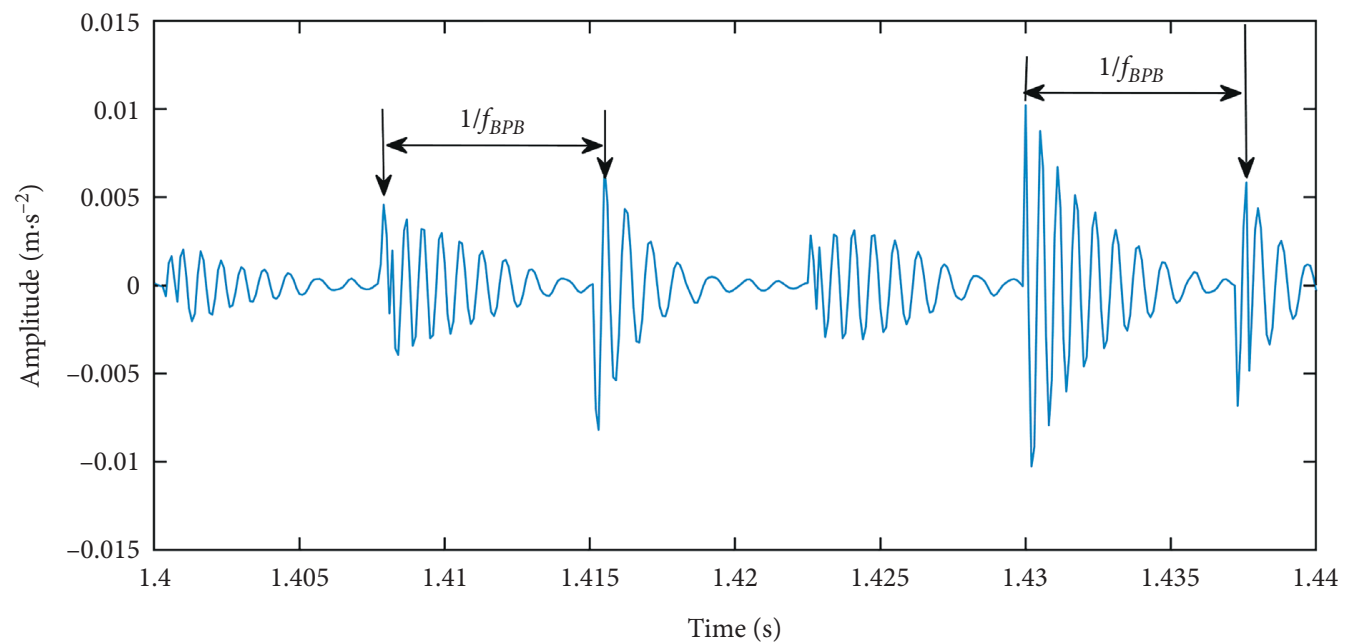

(b)

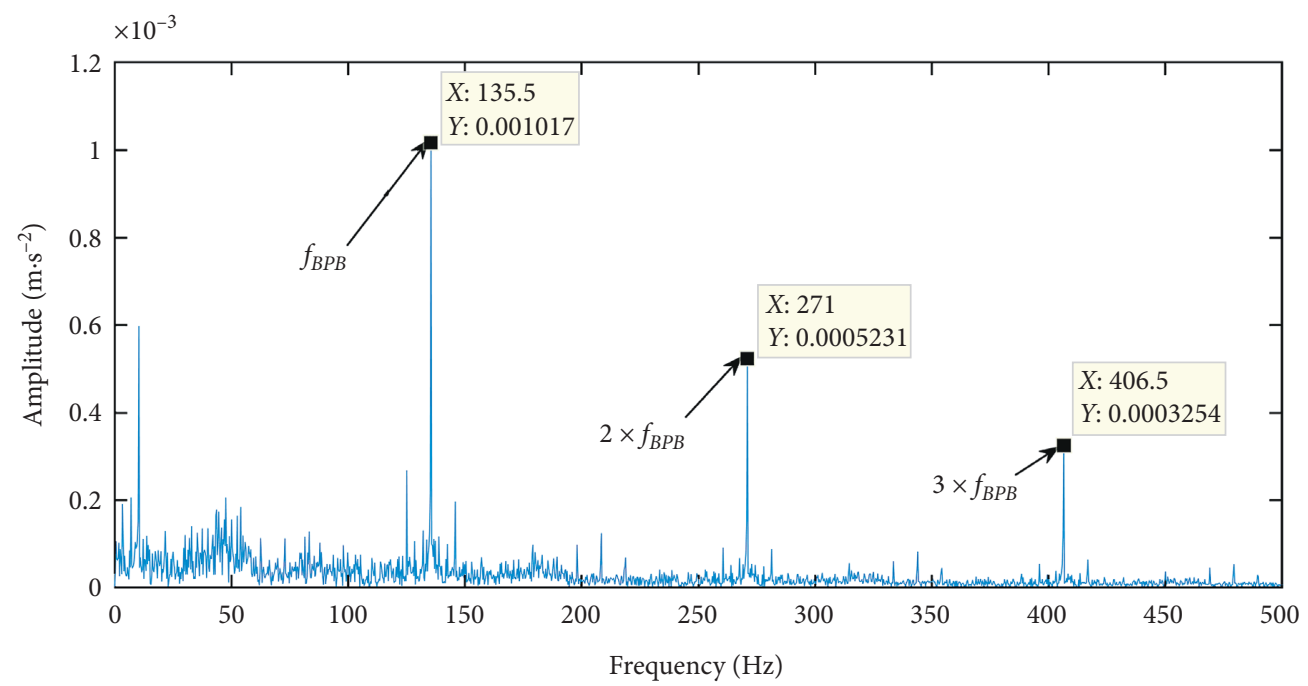

(c)

FIGURE 10: Simulated signals of bearing with element defect. (a) Simulated signals in time domain. (b) Enlarged simulated signals in time domain. (c) Simulation signals in frequency domain. 


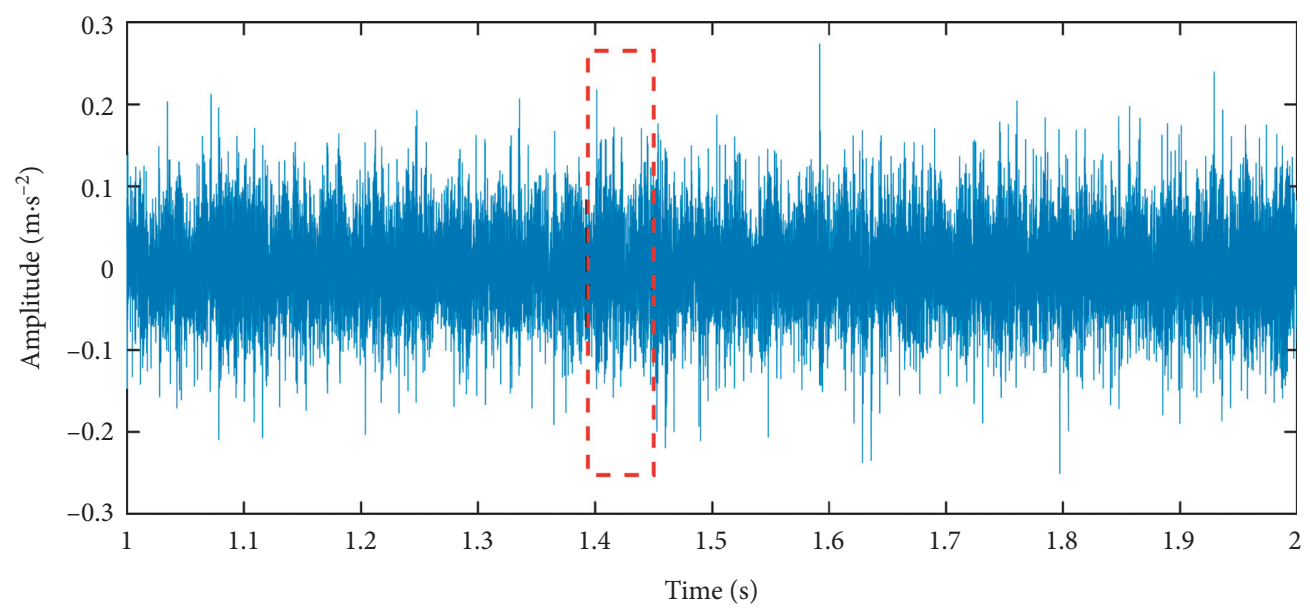

(a)

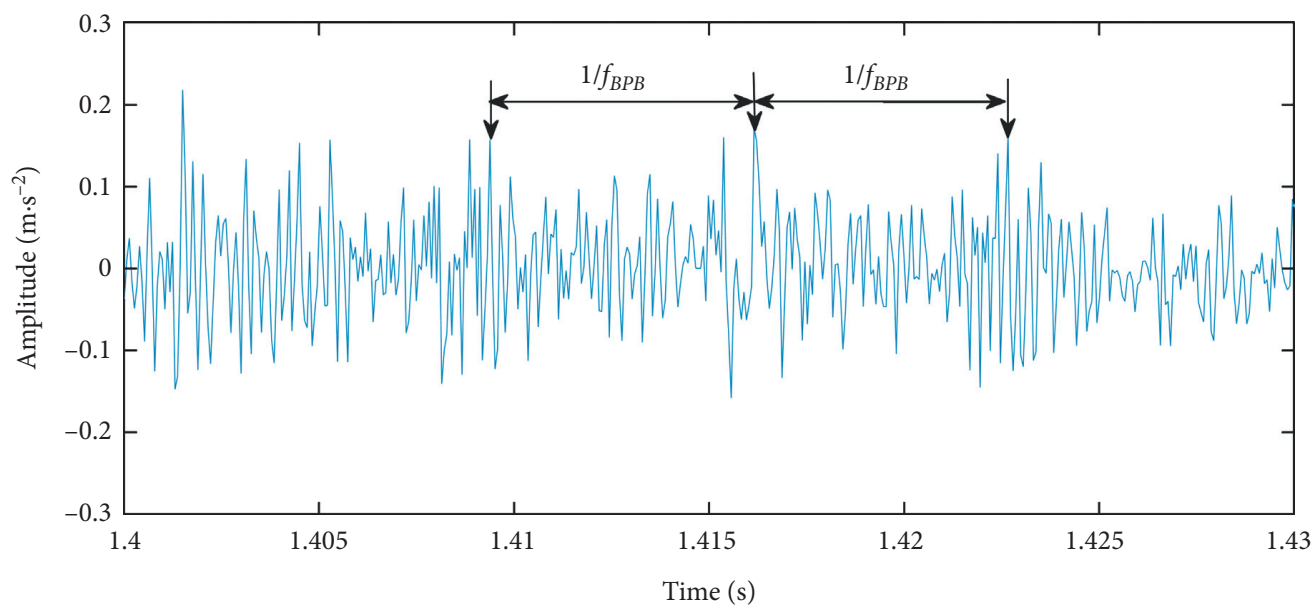

(b)

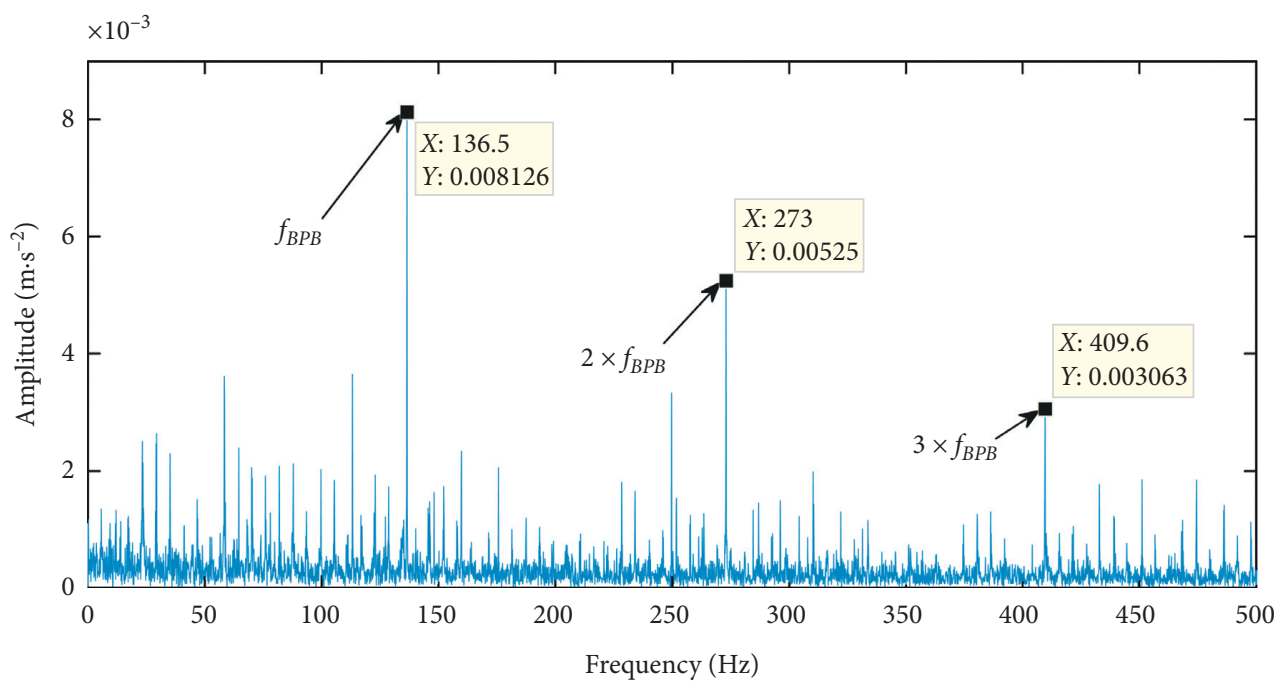

(c)

FIGURE 11: Experimental signals of bearing with element defect. (a) Experimental signals in time domain. (b) Enlarged experimental signals in time domain. (c) Experimental signal in frequency domain. 


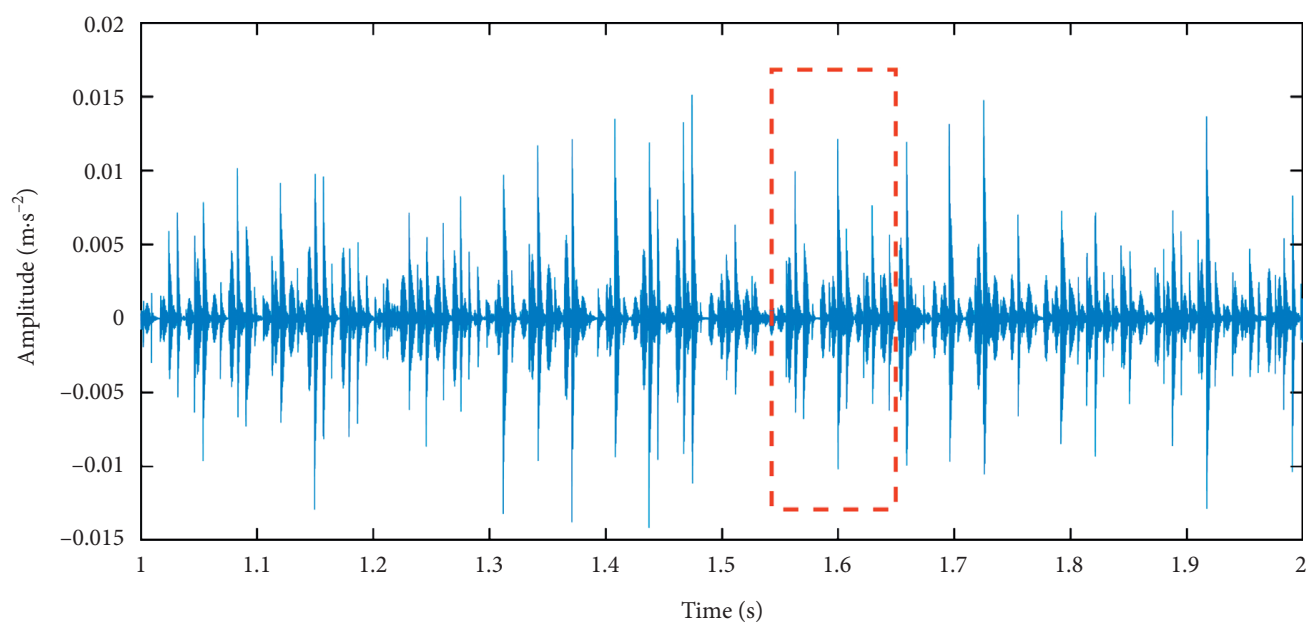

(a)

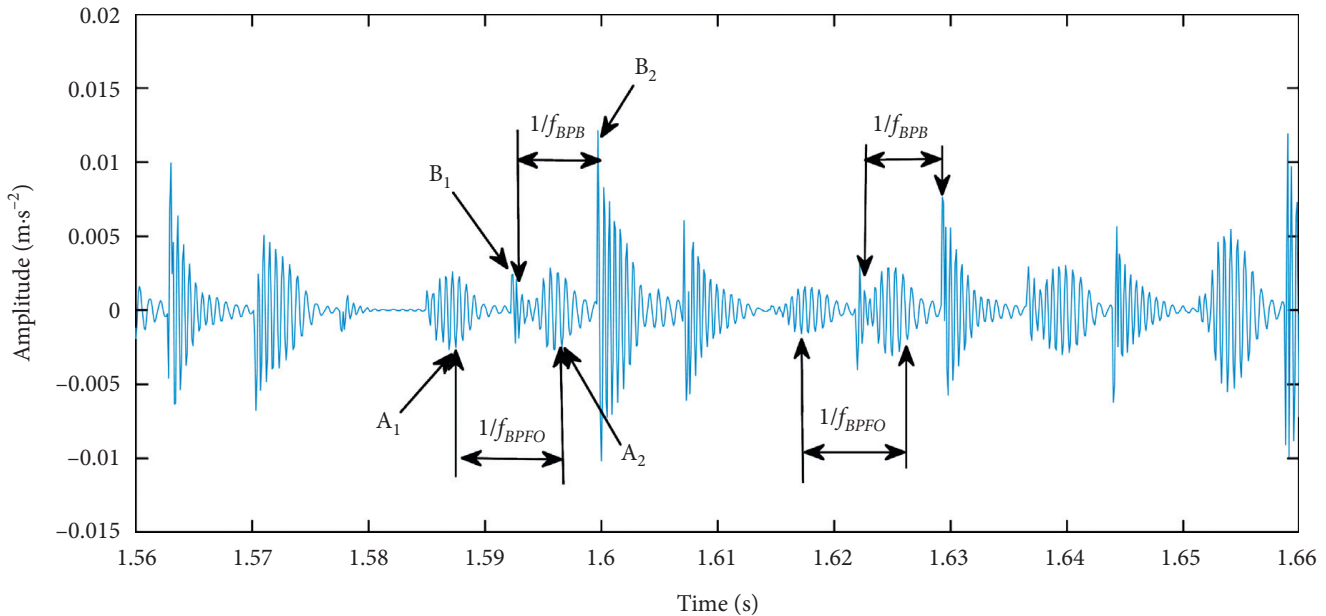

(b)

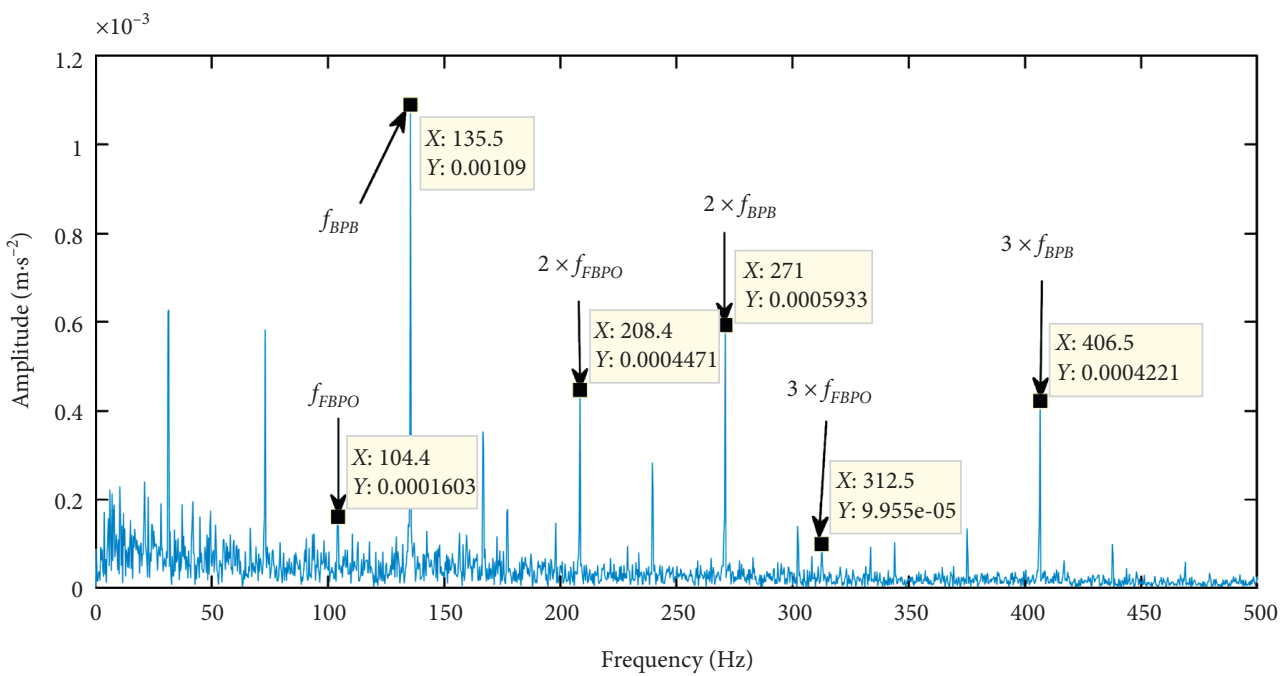

(c)

FiguRE 12: Simulated signals of bearing with compound defect. (a) Simulation signals in time domain. (b) Enlarged simulation signals in time domain. (c) Frequency domain simulation signals. 


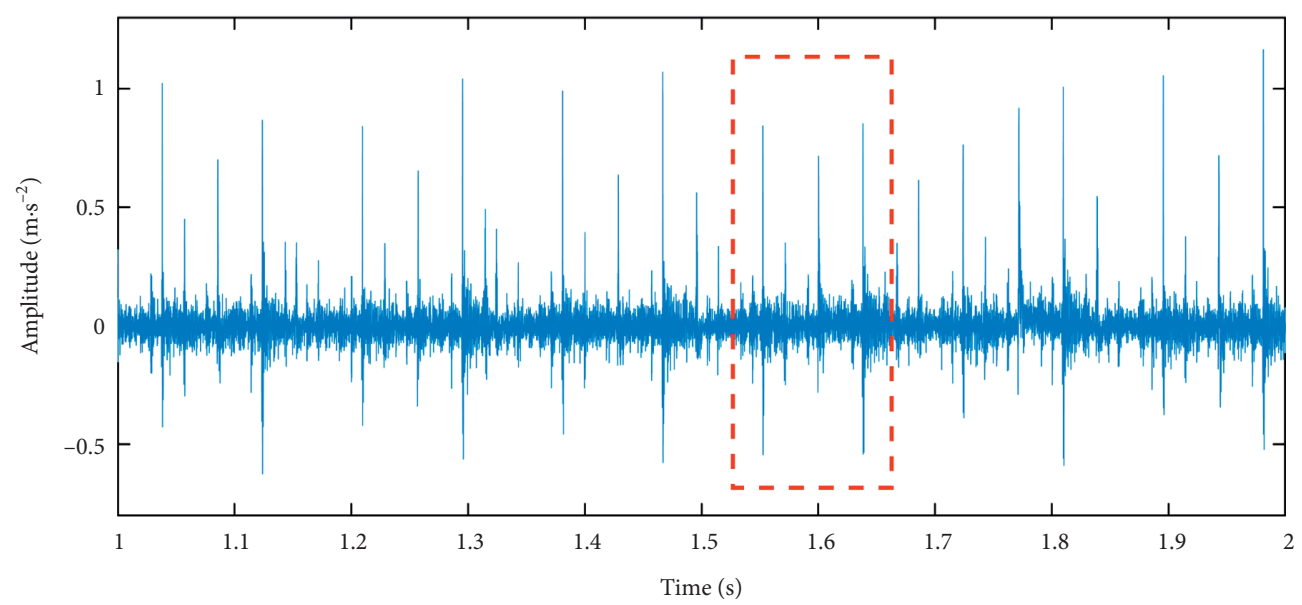

(a)

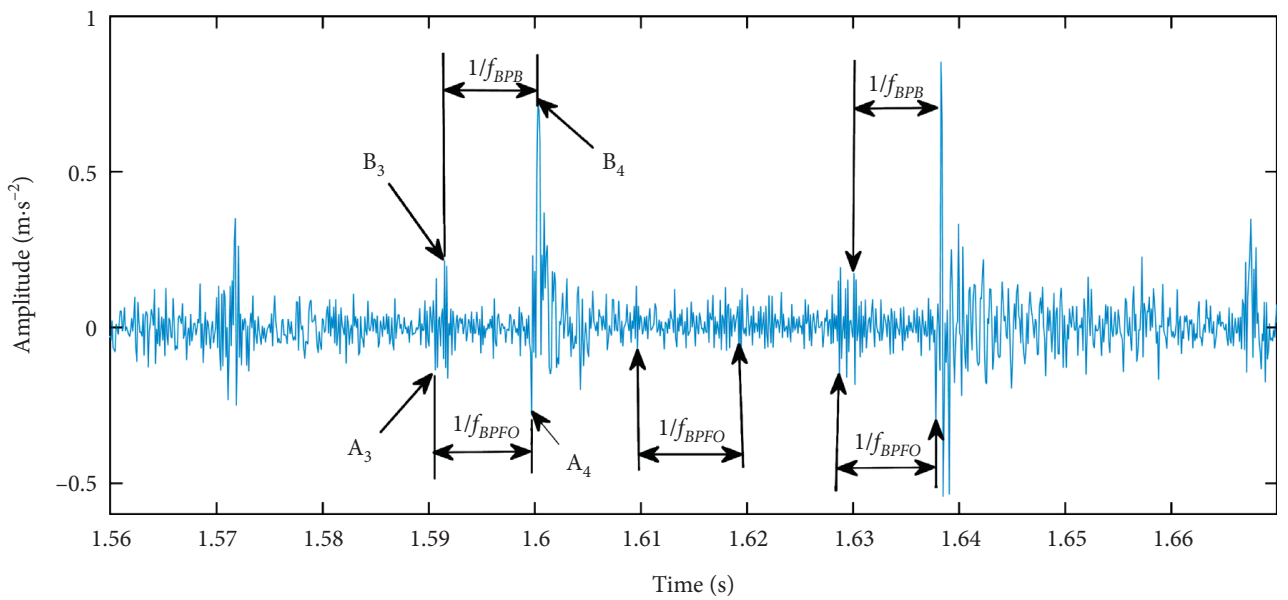

(b)

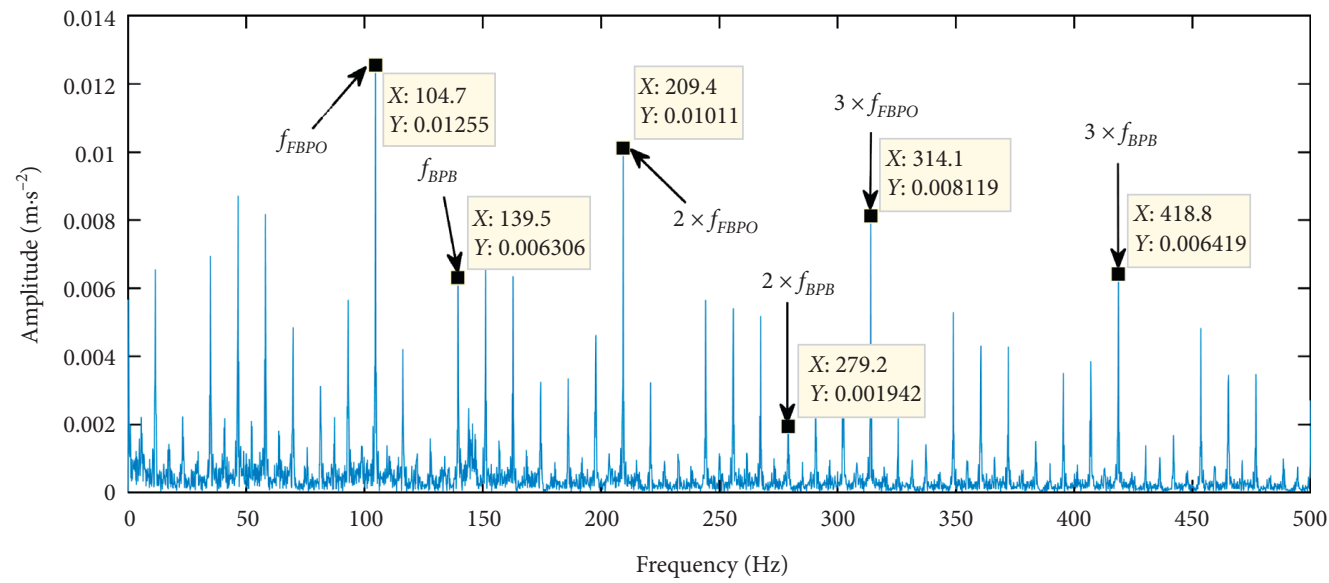

(c)

FIGURE 13: Experimental data of bearing with compound defect. (a) Experimental signals in time domain. (b) Enlarged experimental signals in time domain. (c) Experimental signals in frequency domain.

\section{Vibration Characteristic of Single or Compound Fault Rolling Bearing}

5.1. Influence of Load on Vibration Response of Single or Compound Fault Bearing. When the width of defect on the outer raceway is $1.2 \mathrm{~mm}$, and the diameter of defect on rolling element surface is $1.2 \mathrm{~mm}$, and the shaft speed is $1750 \mathrm{r} / \mathrm{min}$, the applied load on the bearing increases from $10 \mathrm{~N}$ to $150 \mathrm{~N}$, the amplitudes of $f_{\mathrm{BPFO}}, f_{\mathrm{BPB}}$ and their harmonic frequencies can be shown in Figure 14 under three fault modes of rolling element bearing.

From Figure 14, it is shown that the fault characteristic frequencies and their harmonics frequencies do not change, 


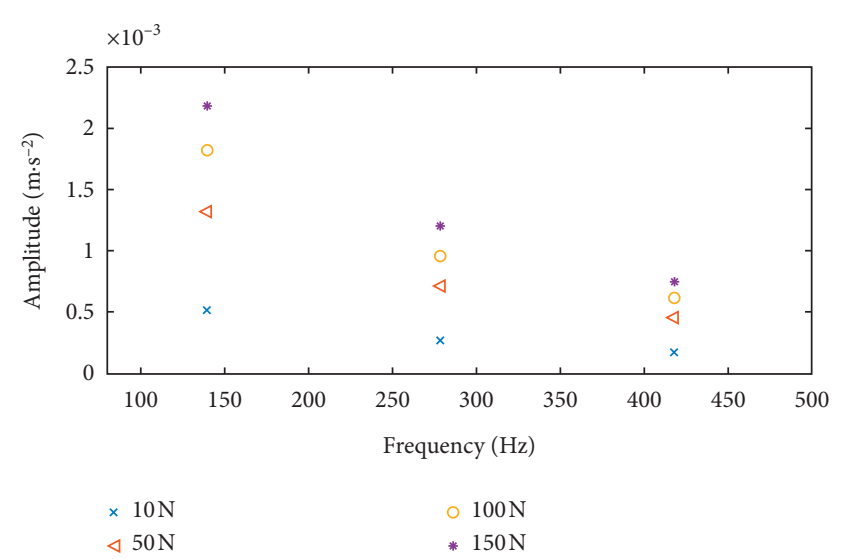

(a)

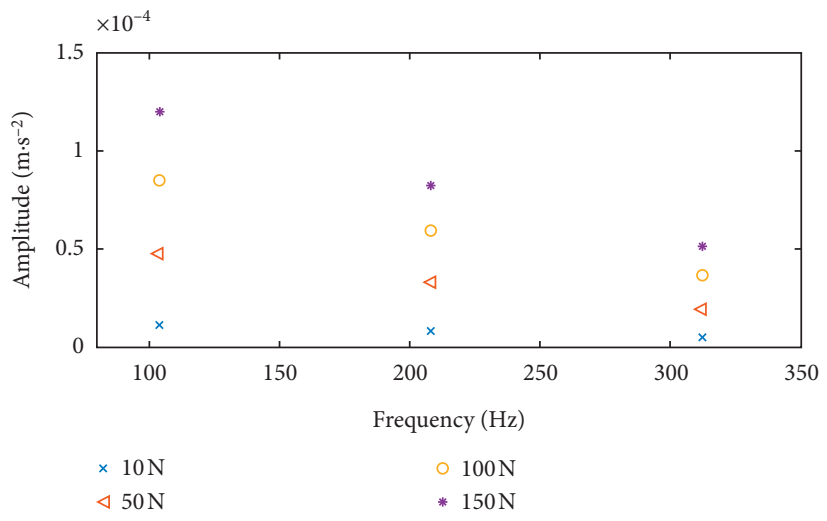

(b)

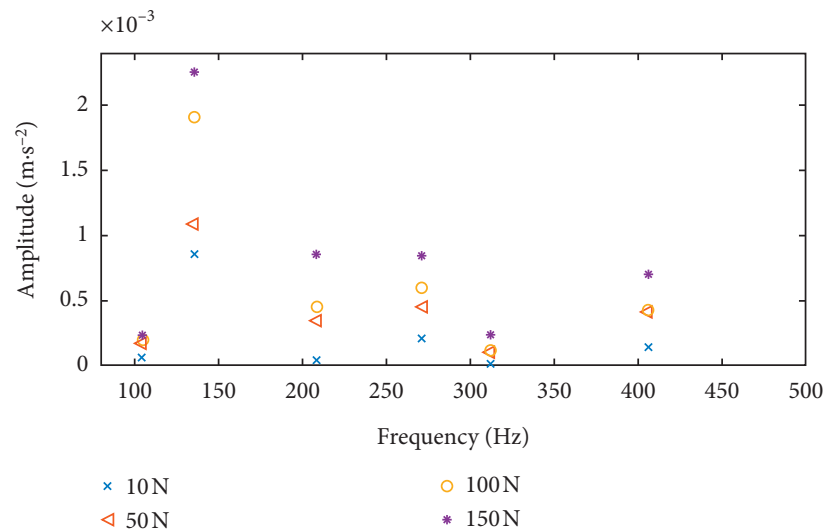

(c)

FIGURE 14: Simulated signals in frequency domains under different load. (a) Simulated signals in frequency domains of element defect. (b) Simulated signals in frequency domains of the outer raceway defect. (c) Simulated signals in frequency domains of compound fault.

but their amplitudes of vibration signal would increase with the increasing of applied load. When the applied load on the bearing is large, the impact load caused by rolling element across the defect would be large, which enhances the vibration response of the bearing correspondently.

\subsection{Influence of Defect Size on Vibration Response of Single or} Compound Fault Bearing. The faults of bearing such as cracks, pitting, pits, and other local defects would occur in operation, and the size of these defects will increase gradually.

When the bearing speed is $1750 \mathrm{r} / \mathrm{min}$ and the applied load is $50 \mathrm{~N}$, the width of defect on the outer raceway and the diameter of defect on rolling element surface are $0.6,0.9,1.2$, and $1.5 \mathrm{~mm}$, respectively. The amplitudes of the fault characteristic frequencies and their harmonic frequencies can be shown in Figure 15.

It can be seen from Figure 15 that the corresponding fault characteristic frequencies and their harmonics frequencies do not change; however, their amplitudes of vibration signal would increase with increasing of the defect size from $0.6 \mathrm{~mm}$ to $1.5 \mathrm{~mm}$. The increase of the defect size of the bearing results in the increase of the internal excitation force; therefore, the amplitudes of vibration response of the bearing vibration would be stronger correspondently. It can explain the relationship between the size of defect and the impact response of the excitation to a certain extent.

5.3. Influence of Rotating Speed on the Vibration Response of Single or Compound Fault Bearing. During the operation of the equipment, the rotating speed has a great influence on the stability of the bearing system, so it is necessary to study the vibration response of the compound fault bearing with different speed.

The width of defect on the outer raceway of bearing is $1.2 \mathrm{~mm}$, the diameter of the defect on rolling element surface is $1.2 \mathrm{~mm}$, and the applied load is $50 \mathrm{~N}$. The amplitudes of the fault characteristic frequencies and their harmonic frequencies can be shown in Figure 16 under the 1550, 1650, 1750 , and $1850 \mathrm{r} / \mathrm{min}$ speed, respectively.

It can be seen from Figure 16 that when the rotating speed increases, the amplitudes of fault characteristic frequencies and their harmonics frequencies would become larger correspondently. With the increase of rotating speed, the impact vibration of the bearing is excited; therefore, the amplitude of the bearing vibration would be increased. 


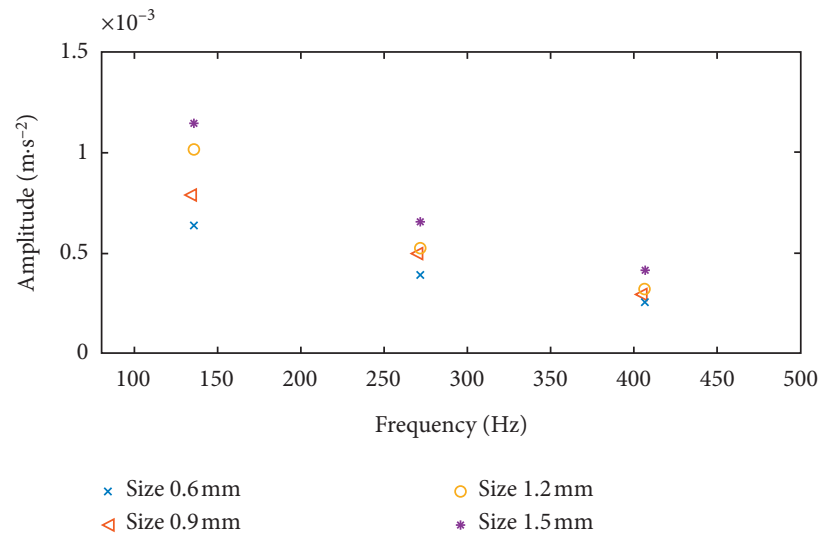

(a)

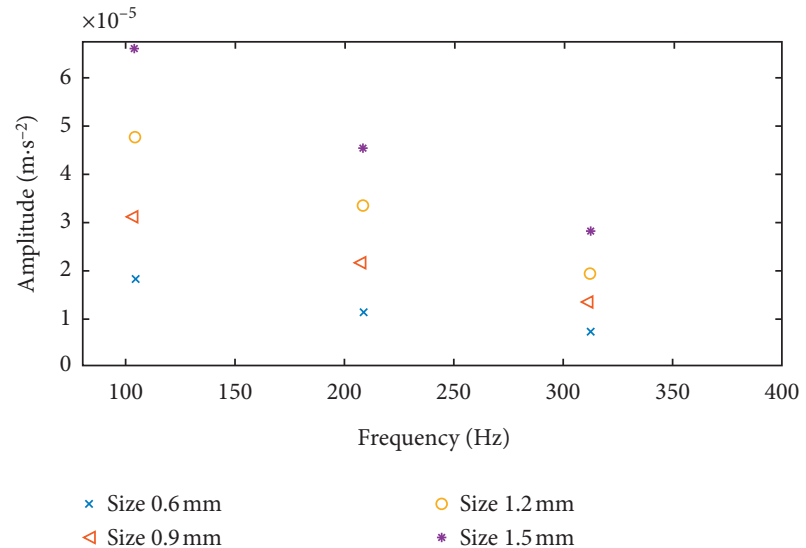

(b)

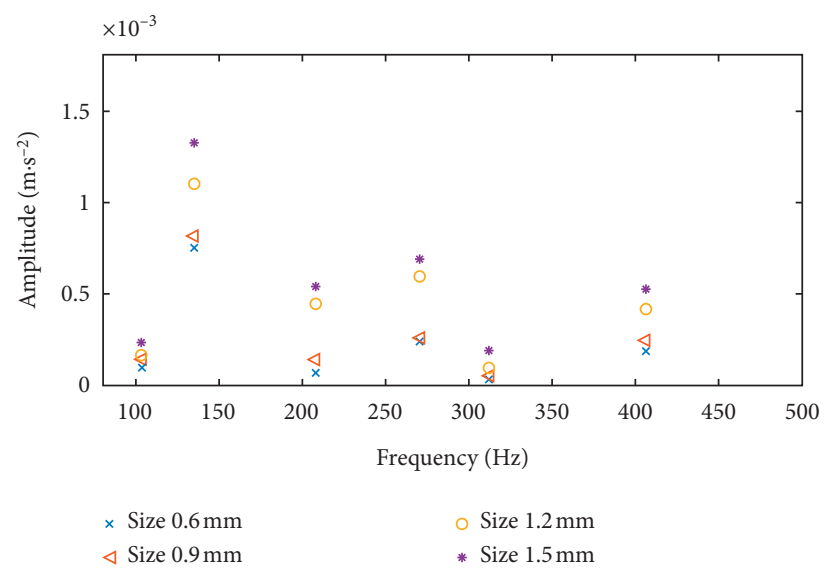

(c)

FiguRE 15: Simulated signals in frequency domain under different defect size. (a) Simulated signals in frequency domains of element defect. (b) Simulated signals in frequency domains of the outer raceway defect. (c) Simulated signals in frequency domains of compound fault.

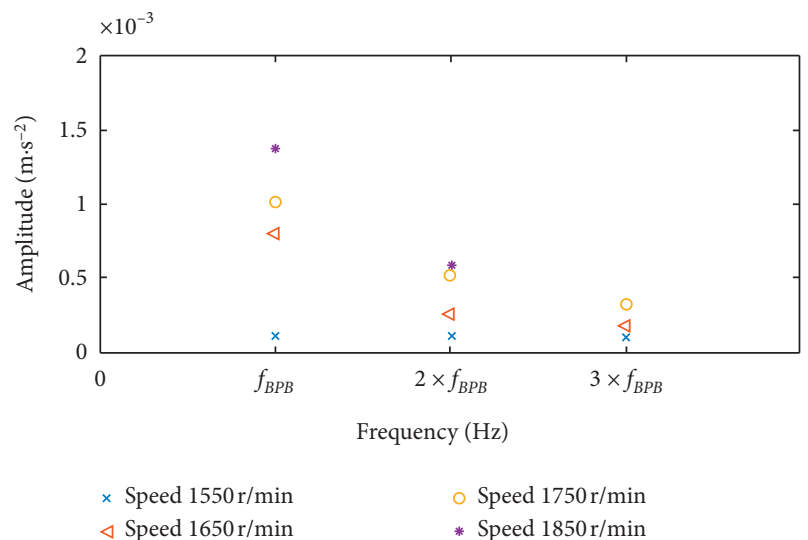

(a)

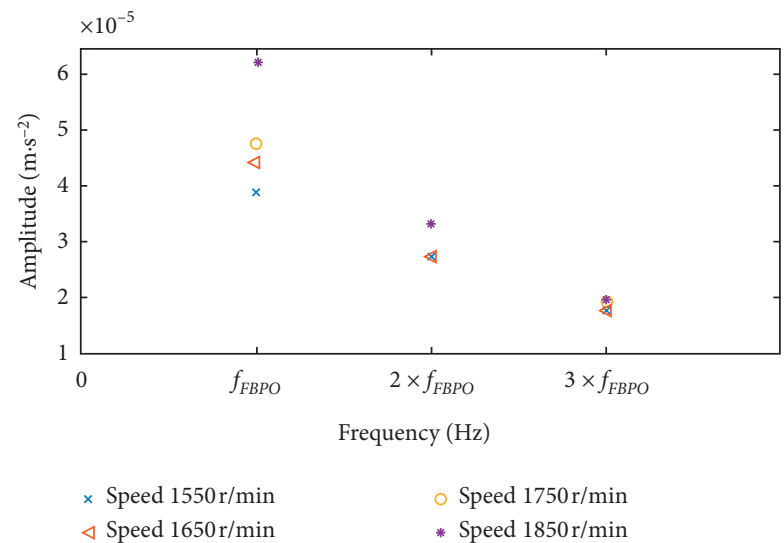

(b)

Figure 16: Continued. 


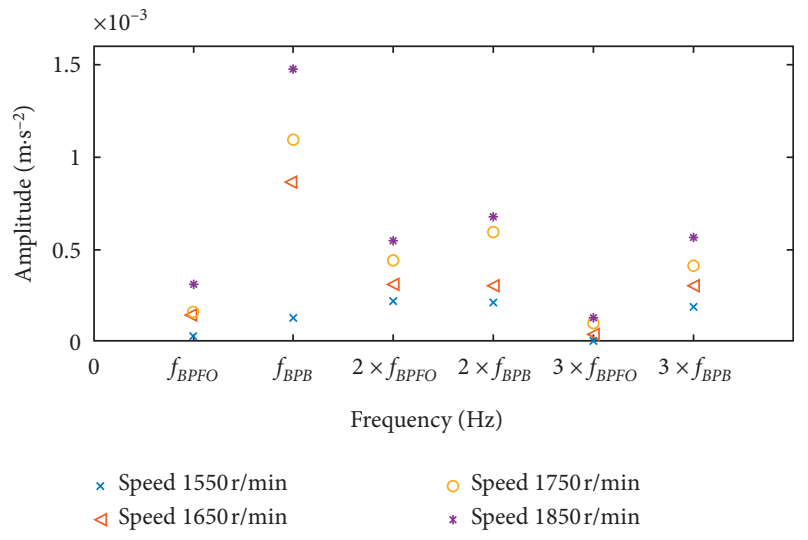

(c)

FiguRE 16: Simulated signals in frequency domain under different shaft rotational speed. (a) Simulated signals in frequency domains of element defect. (b) Simulated signals in frequency domains of the outer raceway defect. (c) Simulated signals in frequency domains of compound fault.

By comparing the simulated signals under different working conditions, it can be clearly seen that with the increasing of rotation speed, defect size, and radial load, the vibration amplitude of bearings would increase correspondently. However, the increase of rotating speed and applied load has a greater impact on the amplitude of $f_{\mathrm{BPFO}}$ and $f_{\mathrm{BPB}}$, which aggravate the vibration impact of the bearing and would accelerate the failure rate and reduce the service life of the bearing.

\section{Conclusions}

(1) Considering time-varying displacement and stiffness, a 4-DOF dynamic model of rolling element bearing with compound fault was established. The fault on rolling element was introduced into the model of compound fault.

(2) The proposed model was verified by the experimental results. It is shown that the proposed model fits the experimental data very well, which can prove the correctness and feasibility of the model.

(3) The influences of compound fault on the vibration response of the bearing were analyzed under different conditions. The results show that both high speed and large load would increase the amplitude of vibration obviously and then accelerate the failure of bearing.

(4) The motion of the rolling element is more complex during the actual operation, and the defect on rolling element may not contact the raceway within every cycle period. This problem should be studied further in the future.

\section{Data Availability}

The data used to support the findings of this study are available from the corresponding author upon request.

\section{Conflicts of Interest}

The authors declare that they have no conflicts of interest regarding the publication of this paper.

\section{Acknowledgments}

This work was supported by the National Natural Science Foundation of China (Grant no. 51765034) and the Hongliu First-Class Disciplines Development Program of Lanzhou University of Technology.

\section{References}

[1] P. D. McFadden and J. D. Smith, "Model for the vibration produced by a single point defect in a rolling element bearing," Journal of Sound and Vibration, vol. 96, no. 1, pp. 69-82, 1984.

[2] Y.-T. Su and S.-J. Lin, "On initial fault detection of a tapered roller bearing: frequency domain analysis," Journal of Sound and Vibration, vol. 155, no. 1, pp. 75-84, 1992.

[3] D. Petersen, C. Howard, and Z. Prime, "Varying stiffness and load distributions in defective ball bearings: analytical formulation and application to defect size estimation," Journal of Sound and Vibration, vol. 337, pp. 284-300, 2015.

[4] S. Singh, U. G. Köpke, C. Q. Howard, and D. Petersen, "Analyses of contact forces and vibration response for a defective rolling element bearing using an explicit dynamics finite element model," Journal of Sound and Vibration, vol. 333, no. 21, pp. 5356-5377, 2014.

[5] D. Shaha Rohit and S. S. Kulkarni, "Vibration analysis of deep groove ball bearing using finite element analysis," International Journal of Engineering Research and Applications, vol. 5, no. 5, pp. 44-50, 2015.

[6] F. Wang, J. Yi, G. Dong, H. Liu, and B. Ji, "Dynamic modelling for vibration analysis of a cylindrical roller bearing due to localized defects on raceways," Proceedings of the Institution of Mechanical Engineers, Part K: Journal of Multi-Body Dynamics, vol. 229, no. 1, pp. 39-64, 2015.

[7] L. Niu, H. Cao, Z. He, and Y. Li, "An investigation on the occurrence of stable cage whirl motions in ball bearings based 
on dynamic simulations," Tribology International, vol. 103, pp. 12-24, 2016.

[8] L. Niu, H. Cao, Z. He, and Y. Li, "A systematic study of ball passing frequencies based on dynamic modeling of rolling ball bearings with localized surface defects," Journal of Sound and Vibration, vol. 357, pp. 207-232, 2015.

[9] P. Yan, C. Yan, K. Wang, F. Wang, and L. Wu, "5-DOF dynamic modeling of rolling bearing with local defect considering comprehensive stiffness under isothermal elastohydrodynamic lubrication," Shock and Vibration, vol. 2020, no. 17, pp. 1-15, 2020.

[10] J. Kang, Y. Lu, Y. Zhang, C. Liu, S. Li, and N. Müller, "Investigation on the skidding dynamic response of rolling bearing with local defect under elastohydrodynamic lubrication," Mechanics \& Industry, vol. 20, no. 6, pp. 615-628, 2019.

[11] J. Liu, M. Shao, and Y. Shao, "Dynamic modeling for rigid rotor bearing systems with a localized defect considering additional deformations at the sharp edges," Journal of Sound and Vibration, vol. 398, pp. 84-102, 2017.

[12] J. Liu and Y. Shao, "An improved analytical model for a lubricated roller bearing including a localized defect with different edge shapes," Journal of Vibration and Control, vol. 24, no. 17, pp. 3894-3907, 2018.

[13] F. Kong, W. Huang, Y. Jiang, W. Wang, and X. Zhao, "A vibration model of ball bearings with a localized defect based on the Hertzian contact stress distribution," Shock and Vibration, vol. 2018, pp. 1-14, 2018.

[14] L. Niu, H. Cao, and X. Xiong, "Dynamic modeling and vibration response simulations of angular contact ball bearings with ball defects considering the three-dimensional motion of balls," Tribology International, vol. 109, pp. 26-39, 2017.

[15] C. Mishra, A. K. Samantaray, and G. Chakraborty, "Bond graph modeling and experimental verification of a novel scheme for fault diagnosis of rolling element bearings in special operating conditions," Journal of Sound and Vibration, vol. 377, pp. 302-330, 2016.

[16] A. Choudhury and N. Tandon, "Vibration response of rolling element bearings in a rotor bearing system to a local defect under radial load," Journal of Tribology, vol. 128, no. 2, pp. 252-261, 2006.

[17] H. Arslan and N. Aktürk, "An investigation of rolling element vibrations caused by local defects," Journal of Tribology, vol. 103, no. 4, p. 41101, 2008.

[18] S. Sassi, B. Badri, and M. Thomas, "A numerical model to predict damaged bearing vibrations," Journal of Vibration and Control, vol. 13, no. 11, pp. 1603-1628, 2007.

[19] H. C. Cheng, Y. M. Zhang, W. J. Lu, and Z. Yang, "Research on ball bearing model based on local defects," SN Applied Science, vol. 1, no. 10, pp. 1219-1229, 2019.

[20] Y. Yang, W. Yang, and D. Jiang, "Simulation and experimental analysis of rolling element bearing fault in rotorbearing-casing system," Engineering Failure Analysis, vol. 92, pp. 205-221, 2018.

[21] X. Yuan, Y.-S. Zhu, and Y.-Y. Zhang, "Multi-body vibration modelling of ball bearing-rotor system considering single and compound multi-defects," Proceedings of the Institution of Mechanical Engineers, Part K: Journal of Multi-Body Dynamics, vol. 228, no. 2, pp. 199-212, 2014.

[22] V. N. Patel, N. Tandon, and R. K. Pandey, "A dynamic model for vibration studies of deep groove ball bearings considering single and multiple defects in races," Journal of Tribology, vol. 132, no. 4, p. 41101, 2010.
[23] V. N. Patel, N. Tandon, and R. K. Pandey, "Vibrations generated by rolling element bearings having multiple local defects on races," Procedia Technology, vol. 14, pp. 312-331, 2014.

[24] M. F. Yaqub, I. Gondal, and J. Kamruzzaman, "Multiplepoints fault signature's dynamics modeling for bearing defect frequencies," International Journal of Mechanical and Mechatronics Engineering, vol. 5, no. 11, pp. 2729-2734, 2011.

[25] K. Wang, C. F. Yan, F. T. Wang, B. Q. Chang, and L. X. Wu, "Dynamic characteristics of compound fault in deep groove ball bearing," Journal of Harbin Institute of Technology, vol. 52, no. 1, pp. 133-140, 2020, in Chinese.

[26] T. Igarashi and J. Kato, "Studies on vibration and sound of defective rolling bearings: third report, vibration of ball bearing with multiple defects," Bulletin of the Japan Society of Mechanical Engineers, vol. 28, no. 237, pp. 492-499, 1985.

[27] Z. Kiral and H. Karagulle, "Vibration analysis of rolling element bearings with various defects under the action of an unbalanced force," Mechanical Systems and Signal Processing, vol. 20, no. 8, pp. 1967-1991, 2006.

[28] X. Liu, H. Huang, and J. Xiang, "A personalized diagnosis method to detect faults in a bearing based on acceleration sensors and an FEM simulation driving support vector machine," Sensors, vol. 20, no. 2, p. 420, 2020.

[29] X. Y. Liu, H. Z. Huang, and J. W. Xiang, "A personalized diagnosis method to detect faults in gears using numerical simulation and extreme learning machine," Knowledge based systems, vol. 195, Article ID 105653, 2020.

[30] Y. B. Dong, M. F. Liao, and Q. Gao, "Dynamics analysis on rolling element bearings with localized defects," Heavy $M a$ chinery, vol. 2012, no. 3, pp. 148-152, 2012, in Chinese.

[31] T. A. Harris and M. N. Kotzalas, Rolling Bearing Analysis Essential Concepts of Bearing Technology, Taylor \& Francis, Abingdon-on-Thames, UK, 5th edition, 2006. 